\title{
Use of vaginal mesh for pelvic organ prolapse repair: a literature review
}

\author{
Virginie Bot-Robin • Jean-Philippe Lucot • \\ Géraldine Giraudet • Chrystèle Rubod • Michel Cosson
}

Received: 15 July 2011 /Accepted: 30 August 2011 / Published online: 9 September 2011

(C) Springer-Verlag 2011

\begin{abstract}
The use of mesh for pelvic organ prolapse repair through the vaginal route has increased during this last decade. The objective is to improve anatomical results (sacropexy with mesh seeming better than traditional surgery) and keep still the advantage of vaginal route. Numbers of cohort series and randomized control trials have been recently published. These works increase our knowledge of advantages and risks of mesh. It has been shown that the use of mesh to treat cystocoele through vaginal route improves anatomical results when compared to traditional surgery. The rate of complications, especially de novo dyspareunia, remains equivalent between the two techniques.
\end{abstract}

Keywords Pelvic organ prolapse - Gynaecologic surgical procedure $\cdot$ Vaginal surgery $\cdot$ Female $\cdot$ Mesh $\cdot$ Review

\section{Background}

Recommendations and reviews were recently published in the USA and in France about the surgical treatment of pelvic organ prolapse (POP) in women. In 2010, a Cochrane review gathered all randomized studies published until February 2009 [1]. Authors concluded that prosthetic

V. Bot-Robin $(\bowtie) \cdot$ J.-P. Lucot $\cdot$ G. Giraudet $\cdot$ C. Rubod $\cdot$

M. Cosson

Department of Gynaecologic Surgery, Jeanne de Flandre Hospital,

Centre Hospitalier Régional et Universitaire,

59000 Lille, France

e-mail: virginiebotrobin@gmail.com

C. Rubod $\cdot$ M. Cosson

Faculty of Medicine, University of 'Lille Nord de France',

59000 Lille, France reinforcement when treating cystocoele by vaginal route seems to lessen the risk of anatomic recurrence, but better satisfaction, better quality of life and decrease of reinterventions could not be demonstrated. There were not enough data to prove the impact of mesh when treating prolapse in the posterior compartment through the vaginal route [1].

Mucowski warned surgeons on the increased number of patients complaining after treatment of POP with prosthetic reinforcement mesh [2]. Over 1,000 undesirable effects were reported between 2005 and 2010 to the US Food and Drug Administration (FDA). A report listed the most frequent due to the technique (vaginal erosion, infection, pelvic pain, urinary problems and recurrence of prolapse). The FDA also encouraged surgeons to declare all adverse effects they could consider linked to the mesh, even those that come under a non-mandatory declaration. Finally, to improve (1) knowledge of surgeons about the possible complications of this procedure and (2) informed counselling provided to concerned women, the International Urogynecological Association and the International Continence Society recently proposed a classification of the complications related directly to the insertion of prostheses in this indication [3].

Since then, several randomized trials and many cohorts were published. Our aim is to collect and analyze them all.

\section{Method}

A computerized bibliographic enquiry on Pubmed used the keywords: "pelvic organ prolapse", "mesh", "graft", "vaginal surgery", with limits: "randomized control trial" and "clinical trial". We added to the review of Savary [4] all randomized trials published in English or French until 
December 2010. To study the adverse effects, we also included prospective or retrospective works. We excluded fundamental studies (using or not animals) and anatomic studies. All included articles were analyzed by two reviewers.

For each randomized study, data were collected on a standardized file which noted: the objectives of the study (main and secondary) with their criteria of judgement (standardized scales), the approval of an ethical committee and the written consent of the patients, the length of inclusion, the calculation of the number of included patients, inclusion and exclusion criteria, the blind definition, the method of randomization, the anatomic level treated, the material used and surgical technique, the method used to homogenize the techniques, surgeons and centres, the statistical method used, the number of patients included and lost to follow-up, the duration of the study and follow-up, the anatomic and functional results, the complications and adverse effects and the conclusions of the authors.

In other studies, we used similar reading files without the items specific to randomized studies.

\section{Findings}

Sixteen randomized trials matching our inclusion criteria were published: one in 2006 [5], two in 2007 [6, 7], four in 2008 [8-11], four in 2009 [12-15] and five in 2010 [1620]. We added two publications of Nieminen, reporting long-term results of the randomized trial initially written by Hiltunen in 2007 [6, 21, 22]. Table 1 sums up for each study the number of patients included, the anatomic level involved, the surgical technique and mesh used and the main and secondary criteria of evaluation. The work of Allahdin was dismissed because of the lack of precision about the conception and the description of surgery [8].

Thirteen of these randomized trials mainly compared traditional surgery and use of mesh on anatomic results [57, 10-14, 17-20, 22]. Twelve studied non-absorbable synthetic (NAS) polypropylene implants $[6,8-12,14,16$, 19-22] and six absorbable biomesh (AB) [5, 7, 13, 15, 17, 18]. Anatomic results are summed up in Table 2.

Improvement of symptoms and quality of life were the main objectives of two studies: Nieminen in 2008 (polypropylene NAS mesh versus colporrhaphy) and Guerette in 2009 (bovine pericardium graft versus colporrhaphy) [13, 21]. They were secondary objectives in the other 15 studies. Among studied symptoms, nine authors took interest in the impact of the mesh reinforcement on sexuality. Nieminen used an original questionnaire as no validated one existed in a Finnish translation. Authors studied not only sexuality but also symptoms and quality of life [21]. For Guerette, sexuality was the main objective: they used the validated questionnaire "Pelvic Organ Prolapse/Urinary Incontinence Sexual Questionnaire" (PISQ-12) [13], also used by Nguyen [10]. Some authors only reported existence or not of a sexual activity and/or pre- and post-surgical dyspareunia. Functional results are summed up in Table 3.

Since December 2010, six randomized studies have been published [23-28]: two studies comparing the anatomical outcomes after 12 months between conventional vaginal prolapse surgery and polypropylene mesh insertion (respectively, $n=189$ versus $n=200$ and $n=97$ versus $n=93$ ) [23, 28], one study comparing the improvement of symptoms and quality of life 2 years after a $2 \times 2$ factorial design first described by Allahdin (Vicryl mesh $n=32$ or not $n=34$ and PDS $n=33$ or Vicryl suture $n=33$ ) [8, 25], one study comparing the anatomical outcomes after 36 months between sacrospinous ligament fixation (SSLF, $n=8$ ) and posterior intravaginal slingplasty (IVS, $n=14$ ) for uterovaginal or vaginal vault prolapse [24], one study comparing the anatomical outcomes after 24 months between laparoscopic sacropexy $(n=53)$ and vaginal mesh (Prolift Kit, $n=$ 55) for the treatment of post hysterectomy vault prolapse [26], and one study comparing the sexual function at 12 months after either a vaginal surgical repair with native tissue or a trocar-guided mesh insertion in patients with recurrent POP [27]. The work of Madhuvrata was also dismissed because of the lack of precision about the conception, the description of surgery and the complication rates for different groups (no mesh versus mesh).

For Maher, the rate of anatomic success (all compartments, state 0 or 1) is significantly higher after sacropexy ( $77 \%$ versus $43 \%$ ) with a higher rate of re-intervention in the Prolift group (79\% versus $87 \%$ ). But the number of symptomatic prolapse is similar [26]. Altman and Withagen showed a number of anatomic failures (state 2 or higher) observed after a tension-free vaginal mesh insertion significantly less important than after a conventional vaginal repair after 12 months (respectively, $65.5 \%$ versus $39.2 \%$ and 45.2 versus 9.6\%) [23, 28]. Heinonen showed a similar rate of anatomic recurrence between the two apical support operations $(21 \%$ in the IVS group and $13 \%$ in the SSLF group) with only one symptomatic patient in each group and no re-intervention [24]. Surgery is significantly shorter for vaginal route when comparing with laparoscopic sacropexy [26], but longer when comparing with conventional vaginal repair [23]. All these studies showed an improvement of quality of life and symptoms of POP in both groups, most often with no significant difference between the two surgical techniques [23, 26-28]. Complications in these recent randomized studies are described in the paragraphs below.

Finally, during the study period, we collected 108 nonrandomized trial (NRT) which studied the surgical treat- 
Table 1 Randomized trials summary

\begin{tabular}{llll}
\hline Trial & Number & $\begin{array}{l}\text { Level of } \\
\text { prolapse }\end{array}$ & Graft type and technique compared \\
\hline Hiltunen 2007 [6] & 202 & ANT & $\begin{array}{c}\text { Polypropylene mesh fixed by } 4 \text { lateral arms } \\
\text { NAS (Parietene }{ }^{\mathbb{R}} \text { ) versus Colporrhaphy }\end{array}$
\end{tabular}

\begin{tabular}{|c|c|c|c|}
\hline Allahdin 2008 [8] & 66 & - & $\begin{array}{l}1^{\circ} \text { Polyglactin mesh AS versus Colporrhaphy } \\
2^{\circ} \text { Polydiaxone suture AS versus Polyglactin } \\
\text { suture AS }\end{array}$ \\
\hline Nguyen 2008 [10] & 76 & ANT & $\begin{array}{l}\text { Polypropylene mesh fixed by } 4 \text { lateral arms } \\
\text { NAS (IntePro }{ }^{\circledR}+\text { Perigee System }{ }^{\circledR} \text { ) versus } \\
\text { Colporrhaphy }\end{array}$ \\
\hline Nieminen 2008 [21] & 202 & ANT & $\begin{array}{l}\text { Polypropylene mesh fixed by } 4 \text { lateral arms } \\
\text { NAS (Parietene }{ }^{\circledR} \text { ) versus Colporrhaphy }\end{array}$ \\
\hline Sivasliolgu 2008 [11] & 90 & ANT & $\begin{array}{l}\text { Polypropylene mesh fixed by } 4 \text { lateral arms } \\
\text { NAS (Parietene }{ }^{\circledR} \text { ) versus Colporrhaphy }\end{array}$ \\
\hline
\end{tabular}

Carey 2009 [12] $\quad 139$ ANT + POST Free Polypropylene mesh NAS

$\left(\right.$ Gynemesh ${ }^{\circledR}$ ) versus Colporrhaphy

Lunardelli 2009 [14] 32 ANT Polypropylene mesh fixed by 4 lateral arms NAS (Nazca TC ${ }^{\circledR}$ ) versus Site-specific surgical anterior vaginal prolapse repair: reinsertion of the pubocervical fascia into the tendinous arch

\begin{tabular}{|c|c|c|c|}
\hline Ek 2010 [16] & 50 & ANT & $\begin{array}{l}\text { Polypropylene mesh fixed by } 4 \text { lateral arms } \\
\text { NAS (Prolift }{ }^{\circledR} \text { ) versus Colporrhaphy }\end{array}$ \\
\hline Iglesia 2010 [19] & 65 & $\mathrm{ANT}+/$ - POST & $\begin{array}{l}\text { Hysterectomy and: Polypropylene mesh } \\
\text { NAS anterior or total (Prolift }{ }^{\circledR} \text { ) versus } \\
\text { Uterosacral ligament suspension as Schull } \\
\text { described or Sacrospinofixation of vaginal } \\
\text { dome as Richter described }\end{array}$ \\
\hline Nieminen 2010 [22] & 202 & ANT & $\begin{array}{l}\text { Polypropylene mesh fixed by } 4 \text { lateral arms } \\
\text { NAS (Parietene }{ }^{\circledR} \text { ) versus Colporrhaphy }\end{array}$ \\
\hline
\end{tabular}

Meschia 2007 [7] $206 \quad$ ANT $\quad$ Porcine skin collagen implant with lateral fixation $\mathrm{AB}\left(\right.$ Pelvicol $\left.^{\circledR}\right)$ versus Plication of the pubocervical fascia

Main objective(s)/Criterion(a)

Secondary objective(s)/Criterion(a)

Anatomic results/POP-Q $<2$ at 2 et 12 months

POP symptoms improvement, per and postsurgical complications, and postvoidal urine residual volume at 2 and 12 months/nonvalidated questionnaire, clinical examination

QoL and POP symptoms improvement /

POPPY (Bugge et al. 2005)

Anatomic results/POP-Q $<2$ at 1 year (intermediate analysis)

Sexual functional results and QoL improvement/validated questionnaire

POP symptoms improvement and sexual functional results/non-validated questionnaire

Anatomic results/POP-Q: $\mathrm{Ba}<-1$ at 1 year

QoL improvement, dyspareunia, cicatrisation and complications/validated questionnaire, clinical examination

Anatomic results/POP-Q $<2$ at 12 years

POP symptoms, QoL and satisfaction improvement/validated questionnaire

Anatomic results/POP-QI with a difference of Ba point of $1 \mathrm{~cm}$ between the 2 groups

Urodynamic examination/MUCP $<40 \mathrm{cmH} 2 \mathrm{O}$

Anatomic results/POP-Q $<2$ at 3 and 12 months

POP symptoms and QoL improvement, complications/validated questionnaire, clinical examination

Anatomic results/POP-Q $<2$ at 3 years

POP symptoms improvement and complications/non-validated questionnaire, clinical examination

Anatomic results / POP-Q $<2$ at 3, 6 and 12 months, then once a year

Complications/clinical examination at 3, 6 and 12 months, then once a year

Guerette 2009 [13] $\quad 94 \quad$ ANT

Bovine pericardium collagen matrix implant with $2 \times 2$ lateral fixation $\mathrm{AB}$ versus Colporrhaphy

Natale 2009 [15] $\quad 190 \quad$ ANT

Porcine skin collagen implant $\mathrm{AB}$ $\left(\right.$ Pelvicol $\left.{ }^{\circledR}\right)$ versus Polypropylene mesh NAS (Gynemesh ${ }^{\circledR}$ )

Feldner 2010 [17] $\quad 56 \quad$ ANT

Porcine collagen implant (submucosa of small intestine) with $3 \times 2$ lateral fixation $\mathrm{AB}$ versus Colporrhaphy

Anatomic results, POP symptoms improvement, sexual functional results, cicatrisation and complications/validated questionnaire, clinical examination, POP-Q at 3, 6, 12 and 24 months

Incidence of erosions/decrease of $15 \%$

POP symptoms and QoL improvement, sexual functional results/validated questionnaire

Anatomic results / POP-Q $<2$ (Ba point) at 1 year

POP symptoms and QoL improvement, complications/validated questionnaire, clinical examination 
Table 1 (continued)

\begin{tabular}{|c|c|c|c|c|}
\hline Trial & Number & $\begin{array}{l}\text { Level of } \\
\text { prolapse }\end{array}$ & Graft type and technique compared & $\begin{array}{l}\text { Main objective(s)/Criterion(a) } \\
\text { Secondary objective(s)/Criterion(a) }\end{array}$ \\
\hline Hviid 2010 [18] & 61 & ANT & $\begin{array}{l}\text { Porcine skin collagen implant with lateral } \\
\text { fixation } \mathrm{AB}\left(\text { Pelvicol }^{\circledR}\right) \text { versus Plication } \\
\text { of the fascia }+ \text { colpectomy }\end{array}$ & $\begin{array}{l}\text { Anatomic results/POP-Q: } \mathrm{Ba}<-1 \text { at } 1 \text { year } \\
\text { QoL improvement/validated questionnaire }\end{array}$ \\
\hline De Tayrac 2008 [9] & 49 & MOY & $\begin{array}{l}\text { Polypropylene mesh with lateral fixation } \\
\text { NAS (IVS }{ }^{\circledR} \text { ) versus Sacrospinofixation }\end{array}$ & $\begin{array}{l}\text { Pain the first day post-surgery/VAS } \\
\text { Operating time, pre- and post-surgical } \\
\text { complications, length of stay, satisfaction, } \\
\text { QoL improvement, sexual activity, anatomic } \\
\text { results, erosion, surgical procedure facility }\end{array}$ \\
\hline Paraiso 2006 [5] & 106 & POST & $\begin{array}{l}\text { Porcine skin implant with central and lateral } \\
\text { fixation }\left(\text { Fortagen }{ }^{\circledR} \text { ) versus Plication of }\right. \\
\text { the fascia or Site-specific surgical repair }\end{array}$ & $\begin{array}{l}\text { Anatomic results/POP-Q: } \mathrm{Bp}<\text { or }=-2 \text { at } \\
1 \text { year } \\
\text { POP symptoms and QoL improvement, sexual } \\
\text { functional results/validated questionnaire }\end{array}$ \\
\hline Lopes 2010 [20] & 32 & POST & $\begin{array}{l}\text { Hysterectomy and: Polypropylene mesh } \\
\text { fixed by } 4 \text { lateral arms NAS (Nazca TC }{ }^{\circledR} \text { ) } \\
\text { versus Sacrospinofixation }+/ \text { - pubocervical } \\
\text { fascia repair if indicated }\end{array}$ & $\begin{array}{l}\text { Anatomic results/POP-Q and POP-Q-I at } \\
1 \text { year } \\
\text { POP symptoms and QoL improvement, } \\
\text { complications/validated questionnaire, } \\
\text { clinical examination }\end{array}$ \\
\hline
\end{tabular}

$P O P$ pelvic organ prolapse, $Q o L$ quality of life, $A S$ absorbable and synthetic, $N A S$ non-absorbable and synthetic, $A B$ absorbable and biologic, MUCP maximum urethral closure pression

ment of POP with reinforcement mesh, mainly NAS meshes (92/108 studies). Complications are described in Tables 4 and 5. It seemed important to distinguish complications due to the dissection or the suspension of the mesh through trans-obturator or trans-levator and the complications due to the mesh itself (vaginal exposition, mesh shrinkage, dyspareunia, infection...).

\section{Bleeding}

In randomized studies, there was no significant difference between the two techniques (traditional surgery or using graft) when comparing "average blood loss" (596 patients in seven studies) [5, 7, 13, 14, 18-20] or "important blood loss" (446 patients in four studies) [6, $9,12,17]$. A superior blood loss in the group with prosthetic reinforcement was found by Hiltunen and Altman $[6,23]$. Heinonen reported one transfusion in the IVS group [24]. Sixty-seven non-randomized studies reported their per-surgical bleeding or post surgical haematomas. However, definition of bleeding varied from one study to another: most often the subjective impression of the surgeon, sometimes a more precise quantification $(>200,300,400,500$ or $1,000 \mathrm{ml})$, or the need of blood transfusion. Other causes of bleeding have been reported as a vascular lesion in concomitant surgery (such as a hysterectomy) [29]. The precise time of onset of important bleeding due to the mesh set up (opening of pararectal or paravesical fossa, passage through trans-obturator or trans-levator) was never reported. No death due to haemorrhage occurred in these series. Post-surgical haematomas were seen in $2.15 \%$ out of 6,034 patients (41 NRT). Their localization and their management were different according to the teams (vaginal mesh, surgical draining, simple clinical monitoring...) and not always explained. Only three studies reported infection of haematoma (three cases out of 368 patients, $0.8 \%$ ); all were seen after using a NAS mesh [30-32]. In the recent randomized studies published, Heinonen reported one haematoma in the IVS group [24], Withagen observed significantly more haematomas in the group with mesh reinforcement [28], and Altman found no difference between the two groups (mesh versus not) [23].

\section{Visceral injury}

Non-randomized studies showed, respectively, 1.94\%, $1.6 \%$ and $1.55 \%$ of bladder, urethral or ureteral injuries, while in randomized studies, these complications were reported, respectively, in three studies for bladder injury (meaning four patients out of 160) [6, 9, 19], one study for urethral injury (one patient out of 29) [17] and one study for ureteral injury (one patient out of 31) [5]. No rectal injury was reported in randomized studies, versus $0.58 \%$ out of 5,877 patients in cohorts (47 NRT). Two nonrandomized studies have mentioned vaginal perforations (4.35\% of 99 patients) [33, 34]. Randomized studies showed no difference with or without mesh reinforcement regarding to these complications, and recently Altman confirmed this result [23]. 
Table 2 Anatomic results (graft surgery versus traditional surgery)

Trial Number Number of patients studied (graft surgery Results (graft surgery versus traditional surgery) versus traditional surgery)

$\begin{array}{lcl}\text { Hiltunen }^{\text {a } 2007[6]} & 202 & \begin{array}{l}2 \text { months: } 201(104 \text { versus } 97) \\ 12 \text { months: } 200(104 \text { versus } 96)\end{array} \\ \text { Nguyen }^{\text {a }} 2008[10] & 76 & 75(37 \text { versus } 38) \\ \text { Sivasliolgu }^{\text {a }} 2008[11] & 90 & 85(43 \text { versus } 42)\end{array}$

$\begin{array}{lrl}\text { Carey }^{\text {a }} \text { 2009 [12] } & 139 & 124(63 \text { versus } 61) \\ \text { Lunardelli 2009 [14] } & 32 & 32(16 \text { versus } 16) \\ \text { Iglesia 2010 [19] } & 65 & 65(32 \text { versus } 33)\end{array}$

Nieminen $2010[22] \quad 202 \quad 182(97$ versus 85$)$

Meschia 2007 [7] $\quad 206 \quad 201(98$ versus 103)

Guerette 2009 [13] $\quad 94 \quad 1$ year: $72(35$ versus 37$)$ 2 years: 44 (17 versus 27$)$

Feldner 2010 [17] $\quad 56 \quad 56(29$ versus 27$)$

Hviid 2010 [18]

Paraiso 2006 [5]

613 months: 50 (27 versus 23 )

12 months: 54 (28 versus 26 )

10681 (26 graft reinforcements versus 27 plication of the fascia versus 28 site-specific surgical repair)

$\begin{array}{lll}\text { Lopes } 2010[20] & 32 & 30(14 \text { versus 16) } \\ \text { De Tayrac }^{\mathrm{b}} \text { 2008 [9] } & 49 & 45(21 \text { versus 24) }\end{array}$

Natale $^{\mathrm{b}} 2009$ [15] $190190\left(96\right.$ Gynemesh $^{\circledR}$ versus 94 Pelvicol $\left.^{\circledR}\right)$
One-year recurrence rate in favour of graft reinforcement (7\% versus $38 \%$ )

One-year recurrence rate in favour of graft reinforcement ( $11 \%$ versus $45 \%)$

One-year recurrence rate in favour of graft reinforcement ( $9 \%$ versus $28 \%$ )

POP-Q difference for points $\mathrm{Aa}, \mathrm{Ba}$ and $\mathrm{C}$ in favour of graft reinforcement

No significant POP-Q difference $<2$ at 1 year $(81 \%$ versus $65.6 \%)$

POP-Q difference for points $\mathrm{Aa}$ and $\mathrm{Ba}$ in favour of graft reinforcement (mean follow-up $=8.5$ months)

No significant difference for recurrence rate with mean follow-up $=9.7$ months ( $59 \%$ versus $72 \%$ )

Point $\mathrm{Ba}$ higher in the group with graft reinforcement

Two-year recurrence rate in favour of graft reinforcement $(12 \%$ versus $41 \%)$

One-year recurrence rate in favour of graft reinforcement for point Ba ( $7 \%$ versus $19 \%)$

No significant difference for recurrence rate on the posterior wall

No significant difference for recurrence rate (15\% versus $22 \%$ after 1 year, $23.5 \%$ versus $37 \%$ after 2 years)

One-year recurrence rate in favour of graft reinforcement (13.8\% versus $40.7 \%)$

POP-Q difference for point $\mathrm{Ba}$ in favour of graft reinforcement

No significant difference for recurrence rate after 3 and 12 months $(15 \%$ versus $7 \%)$

One-year recurrence rate (meaning Bp point $>-2$ ) higher and earlier in the group with graft reinforcement ( $46 \%$ versus $22 \%$ versus $14 \%$ )

No significant difference for recurrence rate between these 3 groups if recurrence is defined by $\mathrm{Bp}>0$

No significant difference for recurrence rate after 12 months whatever level treated

No significant difference for recurrence rate whatever level treated (anterior $4.8 \%$ versus $25 \%$, apex $4.8 \%$ versus $0 \%$, posterior $0 \%$ versus $4.2 \%$ ) with mean follow-up $=16.8$ months

No significant difference for recurrence rate after 24 months $(28.1 \%$ versus $43.6 \%)$

${ }^{a}$ From these trials: number of patients with 1-year follow-up: 247 anterior graft reinforcement NRS versus 236 anterior traditional surgery. Mean recurrence rate after 1 year: with graft reinforcement surgery $=11.5 \%$, without graft reinforcement surgery $=36.35 \%$

${ }^{\mathrm{b}}$ In this study, anatomic results are secondary criteria

\section{Mesh exposition}

The rate of graft exposition, whatever its type (NAS or $\mathrm{AB}$ ) was $7.6 \%$ on average. In randomized studies, it was higher with NAS meshes (most studies): 44 patients out of 398 in nine trials $[6,9-12,14,15,19,20]$. But it varied largely, from $0 \%$ to $35.7 \%$ of cases $[13,17,20]$. Mean frequency of exposition was lower for $\mathrm{AB}$ meshes $(<1 \%)$, excepted in one study [35]. In the majority of randomized trials, mesh expositions were treated with local excision (most often under local anaesthesia) and/or vaginal oestrogen cream [6, $9-12,14,15,20,28]$. A total removal of the mesh in this indication is exceptional. Milani showed that mesh exposure was independently associated with deterioration in sexual function [27].

Infection

Three randomized studies did not show a significant increase of local infection on surgical site [6] or urinary 
Table 3 Functional results (graft surgery versus traditional surgery)

Trial Number Number of patients studied (graft surgery Results (graft surgery versus traditional surgery) versus traditional surgery)

Nieminen $^{\mathrm{a}} 2008[21] \quad 202 \quad 182(97$ versus 85$)$

Guerette $^{\mathrm{a}} 2009$ [13]

941 year: 72 (35 versus 37$)$

2 years: 59 (26 versus 33 )

Hiltunen 2007 [6]

2022 months: 201 (104 versus 97)

12 months: 200 (104 versus 96)

Nguyen 2008 [10] $\quad 76 \quad 75$ (37 versus 38)

Sivasliolgu 2008

[11]

Carey 2009 [12]

Lunardelli 2009 [14]

$3232(16$ versus 16$)$

Ek 2010 [16]

$50 \quad 47(22$ versus 25$)$

Iglesia 2010 [19]

65

65 (32 versus 33$)$

Nieminen 2010 [22] $\quad 202 \quad 182(97$ versus 85)

Meschia 2007 [7]

Natale 2009 [15]

201 (98 versus 103)

$190190\left(96\right.$ Gynemesh $^{\circledR}$ versus 94 Pelvicol ${ }^{\circledR}$ )

Feldner 2010 [17]

Hviid 2010 [18]
$56 \quad 56$ (29 versus 27)

613 months: 50 (27 versus 23$)$

12 months: 54 (28 versus 26 )
Score for vaginal bulge significantly lower in the mesh group 2 years after surgery

Scores for sexual function did not differ between the groups at baseline and 2 years after surgery

Score for dyspareunia significantly lower in the mesh group

Higher rate of patient reported their vagina to be too loose for intercourse in the mesh group

Better UDI-6 score after surgery in both groups

Scores for sexual function did not differ between the groups at baseline and after surgery

Better rate of dyspareunia and PISQ-12 score after surgery in both groups

Majority of the symptoms resolved after surgery in both groups

Symptomatic recurrence higher in mesh group 12 months after surgery $(4 \%$ versus $15 \%)$

Stress urinary incontinence reported more frequently in the mesh group 12 months after surgery ( $23 \%$ versus $10 \%$ )

Better PFDI-20 and PFIQ-7 scores after surgery in both groups

Lower POPDI-6 and UDI-6 scores, and higher CRADI-8 score in the mesh group

Sexual function, PISQ-12 score and rate of dyspareunia did not differ between the groups at baseline and after surgery

Better P-QOL score after surgery in both groups

Worsening PSI-QOL, SUDI, SIIQ and CCCS scores after surgery in both groups

Rate of dyspareunia did not differ between the groups at baseline and after surgery

Similar rate of de novo stress urinary incontinence between the groups after surgery $(6.25 \%)$

Higher rate of de novo stress urinary incontinence in mesh group after surgery ( $32 \%$ versus $8 \%)$

Lower MUCP in mesh group after surgery in overweight women

Lower MUCP in mesh group after surgery in 65-years old or older patients

Better scores about symptoms, quality of life and dyspareunia after surgery in both groups

All symptoms of prolapse resolved after surgery in both groups

Sexual function did not differ between the groups at baseline and 2 years after surgery

Improvement of symptoms of prolapse after surgery in both groups

Improvement of quality of life after surgery in Gynemesh ${ }^{\circledR}$ group in the domains: prolapse impact, social limitations, emotions, and severity measures.

Improvement of quality of life after surgery in Pelvicol ${ }^{\circledR}$ group in all domains with the exclusion of physical limitations

Comparing the postoperative quality of life in both groups: better impact of Pelvicol ${ }^{\circledR}$ in the domains: social limitations and emotions

Better PISQ-12 score after surgery in Pelvicol ${ }^{\circledR}$ group

Comparing the postoperative sexuality in both groups: better impact of Pelvicol ${ }^{\circledR}$

Better P-QOL score after surgery in both groups

Better P-QOL score after surgery in both groups 
Table 3 (continued)

\begin{tabular}{|c|c|c|c|}
\hline Trial & Number & $\begin{array}{l}\text { Number of patients studied (graft surgery } \\
\text { versus traditional surgery) }\end{array}$ & Results (graft surgery versus traditional surgery) \\
\hline De Tayrac 2008 [9] & 49 & 45 (21 versus 24$)$ & $\begin{array}{l}\text { Lower pain and buttock pain in IVS }{ }^{\circledR} \text { group the first day after surgery } \\
\text { No difference of "mean VAS" and "rate of patients with VAS }>5 \text { " in } \\
\text { both groups after long term follow-up ( } 4.8 \text { versus } 12.5 \%) \\
\text { No difference of rate of patients "satisfy" and "very satisfy" in both } \\
\text { groups after long term follow-up ( } 85.7 \% \text { versus } 79.2 \%) \\
\text { Better UDI, POPDI, CRADI, UIQ, CRAIQ and POPIQ score after } \\
\text { surgery in both groups } \\
\text { Absence of improvement of PISQ- } 12 \text { score after surgery in both groups }\end{array}$ \\
\hline Paraiso 2006 [5] & 106 & $\begin{array}{l}81 \text { (26 graft reinforcements versus } 27 \\
\text { plication of the fascia versus } 28 \\
\text { site-specific surgical repair) }\end{array}$ & $\begin{array}{l}\text { Better PFDI-20 and PFIQ-7 scores after surgery in all groups } \\
\text { Better quality of life after surgery in all groups } \\
\text { Better PISQ-12 scores after surgery in all groups } \\
\text { Absence of lower rate of dyspareunia after surgery in all groups }\end{array}$ \\
\hline Lopes 2010 [20] & 32 & $30(14$ versus 16$)$ & $\begin{array}{l}\text { Better quality of life (KHQ) } 1 \text { year after traditional surgery but } \\
\text { without statistically significant difference }\end{array}$ \\
\hline
\end{tabular}

PISQ-12 Pelvic Organ Prolapse/Urinary Incontinence Sexual Questionnaire, UDI-6 Urogenital Distress Inventory Questionnaire, $P F D I-20$ Pelvic Floor Distress Inventory-Short Form Questionnaire, PFIQ-7 Pelvic Floor Impact Questionnaire-Short Form Questionnaire, POPDI-6 Pelvic Organ Prolapse Distress Inventory Questionnaire, CRADI-8 Colorectal-Anal Distress Inventory Questionnaire, $P-Q O L$ Prolapse Quality Of Life Questionnaire, $M U C P$ maximum urethral closure, $K H Q$ King's Health Questionnaire

${ }^{\mathrm{a}}$ In these studies, functional results and sexuality are the main criteria

infection $[10,17]$ in one or other technique. Paraiso was the only one to report a pelvic abscess after surgery [5]. In 11 non-randomized studies (623 patients), nine of which using NAS meshes, no post-surgical infection was detected [33, 36-45]. Six studies with NAS meshes reported post-surgical hyperthermia, meaning $3.15 \%$ out of 755 cases [46-51]. Other frequent infections were urinary, low or high (13 studies, 1,899 patients, mean frequency $5.8 \%$ ), and infection of the surgical site (nine studies, 1,287 patients, mean frequency $2 \%$ ). These complications were mainly seen with NAS grafts (28 out of 32 studies). Deep infection (abscess, cellulites) or generalized infections were reported in 14 cases, four times of which with a prosthesis IVS.
Table 4 Pre- and post-surgery complications in mesh groups

NAS non-absorbable and synthetic, $A S$ absorbable and synthetic

\begin{tabular}{lll}
\hline & Randomized trials & Non randomized trials \\
\hline Major bleeding & $5.3 \%$ & $1.23 \%(0-3.6)$ \\
& 8 patients out of 152 in 4 trials $(1.6 \%$ to $13.8 \%)$ & 29 trials $n=4164$ \\
Blood transfusion & {$[9,12,17,18]$} & $2.05 \%(0-25)$ \\
& $2.1 \%$ & 24 trials $n=3379$ \\
Haematoma & $3 \%$ & $2.15 \%(0-8.3)$ \\
Bladder injury & 4 patients out of 131 in 2 trials $(3.8 \%$ to $9.5 \%)[5,7]$ & 41 trials $n=6034$ \\
& $2.5 \%$ & $1.94 \%(0-8.3)$ \\
Ureteral injury & 4 patients out of 160 in 3 trials $(0 \%$ to $9.6 \%)[6,9,19]$ & 51 trials $n=6827$ \\
& 1 patients out of 31 in 1 trials $[5]$ & $1.55 \%$ \\
Uretral injury & 1 patients out of 29 in 1 trials $[17]$ & 2 trials $n=359$ \\
& & $1.6 \%$ \\
Vaginal injury & 0 & 1 trial $n=123$ \\
Rectal injury & 0 & $4.35 \%(1.6-5.5)$ \\
& & 2 trials $n=99$ \\
& & $0.58 \%$
\end{tabular}




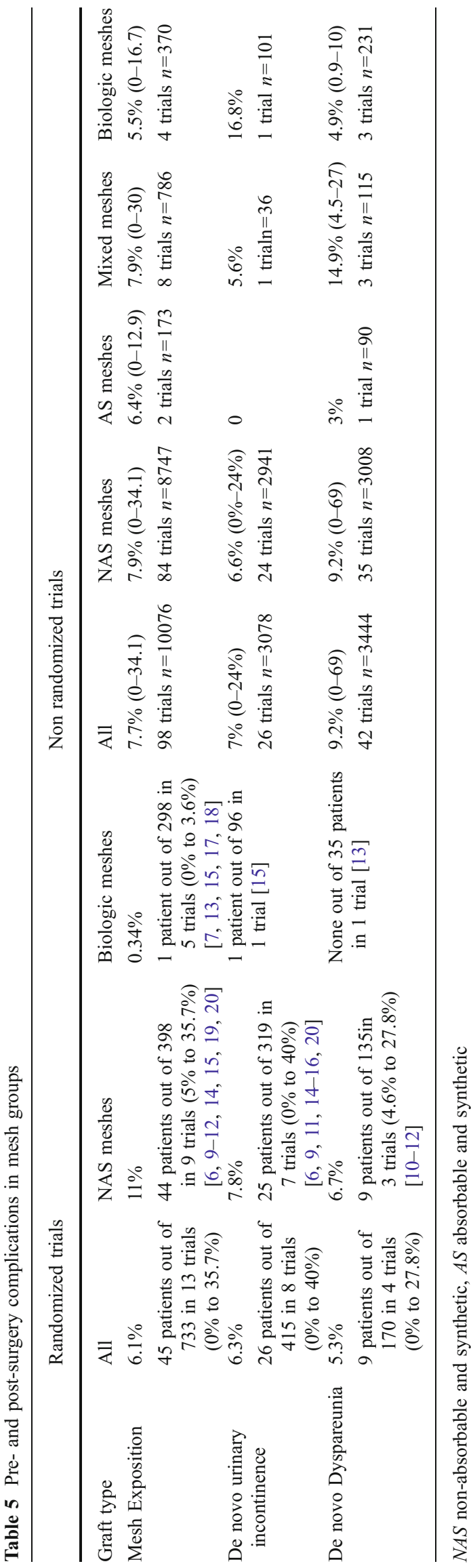

Pain

Mesh shrinkage was reported in $6.8 \%$ of cases but none in randomized studies. Frequency was higher with NAS prosthesis $(7.9 \%)$. Chronic pelvic pain was observed in $5.6 \%$ of patients with mesh. In randomized studies, three chronic pains were described, all in the prosthetic reinforcement group: in the buttock (Lopes, two cases out of 14 patients) [20] or in the leg (Nguyen one case out of 37 patients) [10]. Altman and Withagen did not find a significant difference between both groups for this postoperative symptom $[23,28]$.

Most studies did not specify the type of dyspareunia (de novo or not) or the rate of sexually active patients before and after surgery. Mean rate of dyspareunia in non-randomized studies is $9.2 \%$. In the majority of randomized studies, the rate of postoperative dyspareunia does not differ significantly with or without graft (nine patients out of 170 in four trials) $[10-13,26,28]$.

\section{General complications}

Less frequently, these are reported in Table 6. Two studies on $\mathrm{AB}$ meshes compared the rate of general complications between the two groups: Guerette did not find any significant difference [13], and Feldner found a higher rate in the group with prosthetic reinforcement [17]. Among non-randomized studies, three authors claimed absence of post-surgical complications (for 186 treated patients) [43, 52-54].

De novo stress urinary incontinence

Concerning stress urinary incontinence (SUI), there is a great disparity in definition and assessment between studies: the rates varied from $0 \%$ to $24 \%$. Some authors only included patients without SUI before surgery. Distinction between SUI and urgenturia was not systematic. Five randomized studies evaluated the post-surgical rate of SUI, but only Ek and Altman showed a higher frequency of de novo SUI after prosthetic reinforcement $[16,23]$. When de novo SUI is clearly defined, it was reported in 26 cases out of 415 patients in eight trials $[6,9,11,14-16,20]$.

\section{Discussion}

Number of studies

This literature review shows that many studies have been recently published on cure of prolapse with mesh inserted through the vaginal route. The number of controlled randomized trials and the use of standard questionnaires 
Table 6 Long-term complications in non randomized trials

\begin{tabular}{llll}
\hline Graft type & All kind of meshes & NAS meshes & Biologic meshes \\
\hline Chronic pain (buttock, groin, perinea) & $5.6 \%(0-24.4)$ & $5.8 \%(0-24.4)$ & $0.9 \%$ \\
& 25 trials $n=3307$ & 24 trials $n=3206$ & 1 trial $n=101$ \\
Vesicovaginal or rectovaginal fistula & $1.5 \%(0.3-5)$ & $1.6 \%(0.3-5)$ & $0.9 \%$ \\
& 9 trials $n=1576$ & 8 trials $n=1475$ & 1 trial $n=101$ \\
Shrinkage & $6.8 \%(1.3-17)$ & $7.9 \%(1.3-17)$ & 1.5 \\
& 6 trials $n=1530$ & 5 trials $n=1398$ & 1 trial $n=132$ \\
Vaginal adhesion & $3.1 \%(0.9-6.9 \%)$ & $3.1 \%(0.9-6.9 \%)$ & 0 \\
& 5 trials $n=835$ & 5 trials $n=835$ & \\
Granuloma & $4.7 \%(0.8-13)$ & $4.7 \%(0.8-13)$ & 0 \\
Leukorrhea & 5 trials $n=533$ & 5 trials $n=533$ & \\
& $5.6 \%(0-4)$ & $5.6 \%(0-4)$ & 0 \\
& 4 trials $n=447$ & 4 trials $n=447$ & \\
\hline
\end{tabular}

show the will of real objective evaluation of these techniques. Few surgical techniques have undergone such an assessment, both on anatomic and functional results. But some questionnaires seem unsuited to the specificity of prolapse surgery: for example, they are not very pertinent on sexuality and dyspareunia. Works actually try to adapt them more precisely. Moreover, surgical standards are not always respected: hysterectomy is systematic for Iglesia, though it is classically a risk factor for mesh exposition [19]. Lopes also inserts the synthetic mesh between vagina and fascia, which is not recommended and could explain the rate of vaginal mesh exposition in this study: $35 \%$ [20].

\section{Anatomic results}

For the treatment of cystocoele, five randomized trials on the seven published show that the risk of anatomic recurrence is reduced with NAS mesh. The global rate of relapse at 1 year is estimated around $37 \%$ after traditional surgery ( 87 patients out of 237 ) and at $11 \%$ with NAS mesh (27 patients out of 247) [6,10-12]. We must remain careful: our review does not represent a meta-analysis, and many biases may exist. But NAS meshes seem to bring an anatomic benefit when treating cystocoele. One of these studies demonstrates after a 3-year follow-up the anatomic benefit of NAS meshes (12\% of recurrence after 104 grafts versus $41 \%$ after 96 traditional surgery) [22]. Carey did not find any benefit with a sub-vesical mesh, but in his surgical description, it was the only observation where prosthesis was left free without any suspension [12]. This technical variation seems to be important: in all other studies, subvesical mesh is suspended by its four arms. Carey changed his technique, using a vaginal support device after intervention and during 1 month [55]. Clinical results are not yet enough to conclude, and no comparative study has been published. The second trial showing no benefit of NAS prostheses was stopped after an unacceptable rate of meshes expositions (five patients out of 32, 15\%) [19]. Hysterectomy was also systematic during the cure of cystocoele. The high number of failures at 1 year $(59 \%$ and $72 \%$ ), the concomitant hysterectomy and also the surgeon skills were questioned [56].

Two studies tried to assess the benefit of treating rectocele with a trans-vaginal mesh [5, 20]. For Paraiso, anatomic failures were more important with a biological prosthesis [5]. Lopes did not either find any anatomic benefit in this indication with a synthetic graft [20]. Prerectal mesh cannot be recommended with the actual data. But it seems surprising that a prosthetic surgery more efficient than traditional surgery in the anterior compartment might not be equally in the posterior one. We might need to collect a more important number of cases to show its benefit. Lopes also did not calculate the number of subjects enquired to include.

Treatment of apex is one of the actual discussions in 2011. Suspension to the sacrospinous ligament (SSL) seems the reference technique for the vaginal route. When the four arms of a sub-vesical prosthesis are bound to the tendinous arch of pelvic fascia, apex remains free. Classically SSL is reached by colpotomy and rectal dissection. When there is no rectocele, anterior route by paravesical fossa may be tempted. Prolapse of apex and bladder will be cured in the same surgical time. The sub-vesical prosthesis having several arms: two will be bound to the SSL. Traditional techniques of fixing cannot be used. Two recent systems seem interesting: harpoon or threading $\left(\mathrm{Capio}^{\mathrm{TM}}\right)$. De Tayrac published a series of 48 patients whose sub-vesical prostheses were fixed with $\mathrm{Capio}^{\mathrm{TM}}$ to the SSL by anterior route and also to the tendinous arch of pelvic fascia [57]. The rate of anatomic success was $96 \%$ for cystocoele and $98 \%$ for apex after 8 months follow-up. The cure of apical prolapse cannot only be realised by a sub-vesical obturating prosthesis. Suspension to SSL must be completed by a Richter's traditional method, a posterior prosthesis or an 
anterior one with anterior access of SSL. No technique seems better than the other.

Infracoccygeal sacropexy is described in several publications. The rate of mesh exposition was high, probably due to the multifilament grafts used. Data are scarce, and compilation and analysis of results are difficult as studied populations are heterogeneous (with or without hysterectomy) [58].

Question of moderate and long-term recurrence has recently find answers in several cohorts with longer follow-up. In 2010, Jacquetin showed a stability of anatomic results in the cohort TVM with a three-level surgery after 3 years follow-up [59]. Letouzey reports a rate of failures growing from $11 \%$ at 3 years to $24 \%$ after 5 years follow-up, in the treated compartment (cystocoele) [34]. But in the technical surgery description, authors let the graft free, without suspension. An anatomic failure does not always mean re-intervention: in the TVM cohort, reintervention for anatomic failure was $3 \%$ at 3 years. And Letouzey reports no re-intervention for anatomic failure at 5 years. In January 2011, Maher demonstrates better anatomic results of sacropexy compared to Prolift kit without any difference in functional terms. The rate of anatomic failures after Prolift seems very important (57\%) at 2 years, largely more than literature data and also the rate of re-interventions ( $22 \%$ for all indications, $5 \%$ for pelvic organ prolapse) at 2 years. Such major discrepancies compared to the general results questions the specific skills of the particular teams using this vaginal route [26].

Use of $A B$ meshes does not seem useful: two randomized studies on four published did not show a reduced rate of recurrence when compared to traditional surgery $[13,18]$.

\section{Functional results}

They were evaluated most often by standardized and validated questionnaires. Seven randomized studies evaluated the treatment of cystocoele by meshes. Improvement of urinary symptoms is significant but is equivalent without prosthetic reinforcement. The contradiction between anatomic and functional results leads to question the modalities of evaluation and the criteria used. How can it be explained that symptom scores do get better after traditional surgery though anatomic relapse will reach $37 \%$ ?

De novo urinary incontinence is found in $11 \%$ of women after prosthetic surgery and $7 \%$ after traditional surgery. Only considering sub-vesical NAS prostheses, the rate is $16 \%$ versus $8.5 \%$ in the surgery without mesh. It is difficult to conclude as indications to treat urinary incontinence vary largely from one study to another. Management of urinary symptoms remains a complex chapter we will not open here.

In the two studies of Paraiso and Lopes about vaginal surgery with graft reinforcement in posterior prolapse, functional results were identical when comparing results with or without mesh $[5,20]$.

\section{Complications}

The main complication of prosthetic surgery by vaginal route is mesh exposition. Frequency varies largely from $0 \%$ to $35.7 \%[13,17,20]$. Our increasing knowledge of this particular risk leads to a standardization of surgical technique: no systematic hysterectomy, no inverted-T colpotomy when dissecting cystocoele, infiltration, dissection and positioning of the mesh while keeping the fascia on the vaginal wall, absence of colpectomy, meticulous check-up so there is no transfixion of prosthetic arms in lateral vaginal cul-de-sac. Surgical experience is also linked to the complication rate, with a learning curve evoked by Dwyer [60]. Moreover, management of this complication seems simple enough for most authors. It should not be considered as a major complication.

Infection has become exceptional with the use of polypropylene.

The most dreaded problem is the mesh shrinkage, sometimes with pain and dyspareunia. Its definition is not clear, and the frequency is difficult to evaluate. In cohort studies, the rate of dyspareunia could not be homogenized: the pre- and post-surgical sexual activity figures and inclusion criteria vary (some teams only suggest mesh surgery at time of relapse). There may be sometimes association to other surgery (colpectomy, myorraphy...). Letouzey finds no de novo dyspareunia at 5 years, but the rate is $9 \%(3 / 33)$ in the TVM series [34, 59]. Randomized studies on sexuality and dyspareunia show no significant difference between vaginal surgery with mesh and traditional surgery $[5,9,10,12,13$, $21,22]$. De novo dyspareunia reaches $10 \%$ in average. This rate seems superior than after sacropexy but data vary largely with this technique: Handa reports $14.5 \%$ after sacropexy by laparotomy [61]. There may be improvement of pre-surgical dyspareunia after vaginal prosthetic surgery [13, 21, 59, 62]. In a prospective cohort on 96 patients who underwent placing of a mesh by vaginal route, Hoda found a significant increasing of sexuality with a 2-year follow-up [63]. He signals a transient deterioration during the first 3 months after surgery, which might correspond to healing. But the questionnaires used are not suitable for the evaluation of dyspareunia and sexuality in the post-operative period.

New trends

To reduce surgical risk and post-surgical pain after the trans-obturator or trans-levator passage of the arms, it might be changed for suspension to the tendinous arch of pelvic fascia and also SSL by harpoon, Capio ${ }^{\mathrm{TM}}$ suture capture device, clip or vaginal device. These techniques are being 
evaluated. Suspension of a posterior prosthesis by harpoon (Elevate $^{\mathrm{TM}}$ ) has been reviewed in 139 patients [64]. Authors report one rectal injury during dissection, two haematomas and two buttock pains. On 48 suspensions with $\mathrm{Capio}^{\mathrm{TM}}$, de Tayrac reports: one bladder injury during dissection, two embedded needles, three paravesical haematomas, two ureteral kinking, two major sciatic neuralgias and $54 \%$ of patients had buttock pain during around 8 days (2 to 70 days) [57]. Carey suggests a post-surgical intra-vaginal device but has complications due to dissection: one rectal injury and one paravesical haematoma needing reintervention [55]. In a multicentre study with the same technique $(n=136)$, authors also report two bladder injuries [62]. Intra-vaginal device was lost six times; two devices had to be taken away for infection and two for discomfort. Premature ablation of the device may generate more anatomic failures.

Severe complications were seen with trocars, but they remain exceptional [65]. The complication rate in studies with or without trocars does not seem very different: they most often happened during dissection. Some are specific of the techniques without trocar (kinking, sciatic neuralgia) with no benefit on post-surgical pain. These are preliminary studies and more important series are needed to conclude. Special care must be given to tension when positioning the mesh: when excessive, it becomes a contributing factor to chronic pain, shrinkage, rectal compression [66]. Surgeons must be especially careful when they use a graft without tension adjustment device.

The weight of the non-absorbable material and the elasticity of the mesh seem to favour prosthetic shrinkage. Prostheses used in prolapse surgery stem from hernia surgery and their mechanic properties may be unsuited to vaginal tissues. No author reported anatomic relapse due to the "breaking" of the prosthesis: they may be too robust and rigid. We might wait for meshes specifically developed for genital prolapse. Semi-absorbable mesh with a special knitting and different transversal and longitudinal elasticity was used and published after 1 year of experimentation [31]. Authors report $2 \%$ of de novo dyspareunia but cure of pre-surgical dyspareunia in $76 \%$ of cases and $4 \%$ of de novo pelvic pains. These results may seem encouraging though there are $22 \%$ of anatomic failures in the treated compartment with only 1-year follow-up. Long-term survey is necessary to be sure the benefit for pain is not obtained to the detriment of anatomic results.

\section{Conclusion}

Literature is every day growing, and the use of mesh by vaginal route is now coming to maturity with certain indications and middle-term data. Compared to traditional vaginal surgery, use of a non-absorbable synthetic subvesical mesh to treat cystocoele gives an anatomic benefit. All skilled surgeons have identical functional results and rate of complications, when technical surgical rules are respected. New techniques might give further improvements, but we have yet no sufficient data to conclude. Meshes specifically designed for vaginal surgery might allow even more ameliorations. Comparison with sacropexy by skilled teams (knowing both techniques) might also be interesting.

Declaration of interest Dr. Lucot Jean-Philippe: teaching sessions with Prolift ${ }^{\circledR}$ (Johnson \&Johnson), IPSEN and Endofast ${ }^{\circledR}$ (IBI)

Pr. Cosson Michel: teaching sessions with Prolift ${ }^{\circledR}$ (Johnson \&Johnson), IPSEN, funding for fundamental research Ethicon ${ }^{\circledR}$, patents in progress with Ethicon ${ }^{\circledR}$, Cousin Biotech ${ }^{\circledR}$

\section{References}

1. Maher C, Feiner B, Baessler K, Adams EJ, Hagen S, Glazener CM (2010) Surgical management of pelvic organ prolapse in women. Cochrane Database Syst Rev 4:CD004014

2. Mucowski SJ, Jurnalov C, Phelps JY (2010) Use of vaginal mesh in the face of recent FDA warnings and litigation. Am J Obstet Gynecol 203(2):103, e1-4

3. Haylen BT, Freeman RM, Swift SE, Cosson M, Davila GW, Deprest $J$ et al (2011) An International Urogynecological Association (IUGA)/International Continence Society (ICS) joint terminology and classification of the complications related directly to the insertion of prostheses (meshes, implants, tapes) and grafts in female pelvic floor surgery. Neurourol Urodyn 30 (1):2-12

4. Savary D, Fatton B, Velemir L, Amblard J, Jacquetin B (2009) What about transvaginal mesh repair of pelvic organ prolapse? Review of the literature since the HAS (French Health Authorities) report. J Gynecol Obstet Biol Reprod (Paris) 38 (1): $11-41$

5. Paraiso MF, Barber MD, Muir TW, Walters MD (2006) Rectocele repair: a randomized trial of three surgical techniques including graft augmentation. Am J Obstet Gynecol 195(6):1762-1771

6. Hiltunen R, Nieminen K, Takala T, Heiskanen E, Merikari M, Niemi K et al (2007) Low-weight polypropylene mesh for anterior vaginal wall prolapse: a randomized controlled trial. Obstet Gynecol 110(2 Pt 2):455-462

7. Meschia M, Pifarotti P, Bernasconi F, Magatti F, Riva D, Kocjancic E (2007) Porcine skin collagen implants to prevent anterior vaginal wall prolapse recurrence: a multicenter, randomized study. J Urol 177(1):192-195

8. Allahdin S, Glazener C, Bain C (2008) A randomized controlled trial evaluating the use of polyglactin mesh, polydioxanone and polyglactin sutures for pelvic organ prolapse surgery. J Obstet Gynaecol 28(4):427-431

9. de Tayrac R, Mathe ML, Bader G, Deffieux X, Fazel A, Fernandez H (2008) Infracoccygeal sacropexy or sacrospinous suspension for uterine or vaginal vault prolapse. Int J Gynaecol Obstet 100(2):154-159

10. Nguyen JN, Burchette RJ (2008) Outcome after anterior vaginal prolapse repair: a randomized controlled trial. Obstet Gynecol 111 (4):891-898 
11. Sivaslioglu AA, Unlubilgin E, Dolen I (2008) A randomized comparison of polypropylene mesh surgery with site-specific surgery in the treatment of cystocoele. Int Urogynecol J Pelvic Floor Dysfunct 19(4):467-471

12. Carey M, Higgs P, Goh J, Lim J, Leong A, Krause H et al (2009) Vaginal repair with mesh versus colporrhaphy for prolapse: a randomized controlled trial. BJOG 116(10):1380-1386

13. Guerette NL, Peterson TV, Aguirre OA, Vandrie DM, Biller DH, Davila GW (2009) Anterior repair with or without collagen matrix reinforcement: a randomized controlled trial. Obstet Gynecol 114 (1):59-65

14. Lunardelli JL, Auge AP, Lemos NL, Carramao Sda S, de Oliveira AL, Duarte E et al (2009) Polypropylene mesh vs. site-specific repair in the treatment of anterior vaginal wall prolapse: preliminary results of a randomized clinical trial. Rev Col Bras Cir 36(3):210-216

15. Natale F, La Penna C, Padoa A, Agostini M, De Simone E, Cervigni M (2009) A prospective, randomized, controlled study comparing Gynemesh, a synthetic mesh, and Pelvicol, a biologic graft, in the surgical treatment of recurrent cystocoele. Int Urogynecol J Pelvic Floor Dysfunct 20(1):75-81

16. Ek M, Tegerstedt G, Falconer C, Kjaeldgaard A, Rezapour M, Rudnicki $M$ et al (2010) Urodynamic assessment of anterior vaginal wall surgery: a randomized comparison between colporraphy and transvaginal mesh. Neurourol Urodyn 29(4):527-531

17. Feldner PC Jr, Castro RA, Cipolotti LA, Delroy CA, Sartori MG, Girao MJ (2010) Anterior vaginal wall prolapse: a randomized controlled trial of SIS graft versus traditional colporrhaphy. Int Urogynecol J Pelvic Floor Dysfunct 21(9):1057-1063

18. Hviid U, Hviid TV, Rudnicki M (2010) Porcine skin collagen implants for anterior vaginal wall prolapse: a randomized prospective controlled study. Int Urogynecol J Pelvic Floor Dysfunct 21(5):529-534

19. Iglesia CB, Sokol AI, Sokol ER, Kudish BI, Gutman RE, Peterson JL et al (2010) Vaginal mesh for prolapse: a randomized controlled trial. Obstet Gynecol 116(2 Pt 1):293-303

20. Lopes ED, Lemos NL, Carramao Sda S, Lunardelli JL, Ruano JM, Aoki $\mathrm{T}$ et al (2010) Transvaginal polypropylene mesh versus sacrospinous ligament fixation for the treatment of uterine prolapse: 1-year follow-up of a randomized controlled trial. Int Urogynecol J Pelvic Floor Dysfunct 21(4):389-394

21. Nieminen K, Hiltunen R, Heiskanen E, Takala T, Niemi K, Merikari M et al (2008) Symptom resolution and sexual function after anterior vaginal wall repair with or without polypropylene mesh. Int Urogynecol J Pelvic Floor Dysfunct 19(12):1611-1616

22. Nieminen K, Hiltunen R, Takala T, Heiskanen E, Merikari M, Niemi K et al (2010) Outcomes after anterior vaginal wall repair with mesh: a randomized, controlled trial with a 3 year follow-up. Am J Obstet Gynecol 203(3):235, e1-8

23. Altman D, Vayrynen T, Engh ME, Axelsen S, Falconer C (2011) Anterior colporrhaphy versus transvaginal mesh for pelvic-organ prolapse. N Engl J Med 364(19):1826-1836

24. Heinonen PK, Nieminen K (2011) Combined anterior vaginal wall mesh with sacrospinous ligament fixation or with posterior intravaginal slingplasty for uterovaginal or vaginal vault prolapse. Eur J Obstet Gynecol Reprod Biol 157(2):230-233

25. Madhuvrata P, Glazener C, Boachie C, Allahdin S, Bain C (2011) A randomized controlled trial evaluating the use of polyglactin (Vicryl) mesh, polydioxanone (PDS) or polyglactin (Vicryl) sutures for pelvic organ prolapse surgery: outcomes at 2 years. J Obstet Gynaecol 31(5):429-435

26. Maher CF, Feiner B, DeCuyper EM, Nichlos CJ, Hickey KV, O'Rourke P (2011) Laparoscopic sacral colpopexy versus total vaginal mesh for vaginal vault prolapse: a randomized trial. Am J Obstet Gynecol 204(4):360, e1-7
27. Milani AL, Withagen MI, The HS, Nedelcu-van der Wijk I, Vierhout ME (2011) Sexual function following trocar-guided mesh or vaginal native tissue repair in recurrent prolapse: a randomized controlled trial. J Sex Med. doi:10.1111/j.17436109.2011.02392.x

28. Withagen MI, Milani AL, den Boon J, Vervest HA, Vierhout ME (2011) Trocar-guided mesh compared with conventional vaginal repair in recurrent prolapse: a randomized controlled trial. Obstet Gynecol 117(2 Pt 1):242-250

29. Apfelbaum D, David-Montefiore E, Darai E (2009) Mid-term results of the grade 3-4 genital prolapse cure by vaginal route using a total hammock of porcine skin implant associated with bilateral sacro-spinofixation. J Gynecol Obstet Biol Reprod (Paris) 38(2): $125-132$

30. de Tayrac R, Devoldere G, Renaudie J, Villard P, Guilbaud O, Eglin G (2007) Prolapse repair by vaginal route using a new protected low-weight polypropylene mesh: 1-year functional and anatomical outcome in a prospective multicentre study. Int Urogynecol J Pelvic Floor Dysfunct 18(3):251-256

31. Milani AL, Hinoul P, Gauld JM, Sikirica V, van Drie D, Cosson M (2011) Trocar-guided mesh repair of vaginal prolapse using partially absorbable mesh: 1 year outcomes. Am J Obstet Gynecol 204(1):74, e1-8

32. Sergent F, Sentilhes L, Resch B, Diguet A, Verspyck E, Marpeau L (2007) Prosthetic repair of genito-urinary prolapses by the transobturateur infracoccygeal hammock technique: medium-term results. J Gynecol Obstet Biol Reprod (Paris) 36(5):459-467

33. Araco F, Gravante G, Overton J, Araco P, Dati S (2009) Transvaginal cystocoele correction: Midterm results with a transobturator tension-free technique using a combined bovine pericardium/polypropylene mesh. J Obstet Gynaecol Res 35(5):953960

34. Letouzey V, Deffieux X, Gervaise A, Mercier G, Fernandez H, de Tayrac R (2010) Trans-vaginal cystocoele repair using a tensionfree polypropylene mesh: more than 5 years of follow-up. Eur J Obstet Gynecol Reprod Biol 151(1):101-105

35. Simsiman AJ, Luber KM, Menefee SA (2006) Vaginal paravaginal repair with porcine dermal reinforcement: correction of advanced anterior vaginal prolapse. Am J Obstet Gynecol 195(6):1832-1836

36. Balakrishnan S, Lim YN, Barry C, Corstians A, Kannan K, Rane A (2008) Prospective evaluation of the safety and efficacy of the Apogee system for treatment of vault prolapse. J Obstet Gynaecol 28(6):618-620

37. Lee YS, Han DH, Lim SH, Kim TH, Choo MS, Seo JT et al (2010) Efficacy and Safety of "Tension-free" Placement of Gynemesh PS for the Treatment of Anterior Vaginal Wall Prolapse. Int Neurourol J 14(1):34-42

38. Lin TY, Su TH, Huang WC (2010) Polypropylene mesh used for adjuvant reconstructive surgical treatment of advanced pelvic organ prolapse. J Obstet Gynaecol Res 36(5):1059-1063

39. Mahdy A, Elmissiry M, Ghoniem G (2008) The outcome of transobturator cystocoele repair using biocompatible porcine dermis graft: our experience with 32 cases. Int Urogynecol J Pelvic Floor Dysfunct 19(12):1647-1652

40. Moore RD, Miklos JR (2009) Vaginal repair of cystocoele with anterior wall mesh via transobturator route: efficacy and complications with up to 3-year followup. Adv Urol 2009:743831

41. Okui N, Okui M, Horie S (2009) Improvements in overactive bladder syndrome after polypropylene mesh surgery for cystocoele. Aust N Z J Obstet Gynaecol 49(2):226-231

42. Rane A, Kannan K, Barry C, Balakrishnan S, Lim Y, Corstiaans A (2008) Prospective study of the Perigee system for the management of cystocoeles - medium-term follow up. Aust N Z J Obstet Gynaecol 48(4):427-432 
43. Sentilhes L, Sergent F, Resch B, Berthier A, Verspyck E, Marpeau L (2006) Prolapsus isolé de l'étage postérieur posthystérectomie: résultats préliminaires d'une technique utilisant les voies vaginales et transobturatrice basse. Ann Chir 131:533-539

44. van Raalte HM, Lucente VR, Molden SM, Haff R, Murphy M (2008) One-year anatomic and quality-of-life outcomes after the Prolift procedure for treatment of posthysterectomy prolapse. Am J Obstet Gynecol 199(6):694, e1-6

45. Withagen MI, Vierhout ME, Milani AL (2010) Does trocar-guided tension-free vaginal mesh (Prolift) repair provoke prolapse of the unaffected compartments? Int Urogynecol J Pelvic Floor Dysfunct 21(3):271-278

46. Abdel-Fattah M, Ramsay I (2008) Retrospective multicentre study of the new minimally invasive mesh repair devices for pelvic organ prolapse. BJOG 115(1):22-30

47. Eboue C, Marcus-Braun N, von Theobald P (2010) Cystocele repair by transobturator four arms mesh: monocentric experience of first 123 patients. Int Urogynecol J Pelvic Floor Dysfunct 21(1):85-93

48. Fatton B, Amblard J, Debodinance P, Cosson M, Jacquetin B (2007) Transvaginal repair of genital prolapse: preliminary results of a new tension-free vaginal mesh (Prolift technique) - a case series multicentric study. Int Urogynecol J Pelvic Floor Dysfunct 18(7):743-752

49. Gagnon LO, Tu LM (2010) Mid-term results of pelvic organ prolapse repair using a transvaginal mesh: the experience in Sherbooke, Quebec. Can Urol Assoc J 4(3):188-191

50. Ganj FA, Ibeanu OA, Bedestani A, Nolan TE, Chesson RR (2009) Complications of transvaginal monofilament polypropylene mesh in pelvic organ prolapse repair. Int Urogynecol J Pelvic Floor Dysfunct 20(8):919-925

51. Wetta LA, Gerten KA, Wheeler TL 2nd, Holley RL, Varner RE, Richter HE (2009) Synthetic graft use in vaginal prolapse surgery: objective and subjective outcomes. Int Urogynecol J Pelvic Floor Dysfunct 20(11):1307-1312

52. Migliari R, De Angelis M, Madeddu G, Verdacchi T (2000) Tension-free vaginal mesh repair for anterior vaginal wall prolapse. Eur Urol 38(2):151-155

53. Migliari R, Usai E (1999) Treatment results using a mixed fiber mesh in patients with grade IV cystocoele. J Urol 161(4):1255-1258

54. Sand PK, Koduri S, Lobel RW, Winkler HA, Tomezsko J, Culligan PJ et al (2001) Prospective randomized trial of polyglactin 910 mesh to prevent recurrence of cystocoeles and rectoceles. Am J Obstet Gynecol 184(7):1357-1362, discussion 62-4

55. Carey M, Slack M, Higgs P, Wynn-Williams M, Cornish A (2008) Vaginal surgery for pelvic organ prolapse using mesh and a vaginal support device. BJOG 115(3):391-397
56. Jacquetin B, Cosson M, Debodinance P, Hinoul P (2010) Vaginal mesh for prolapse: a randomized controlled trial. Obstet Gynecol 116(6):1457-1458, author reply 8

57. de Tayrac R, Boileau L, Fara JF, Monneins F, Raini C, Costa P (2010) Bilateral anterior sacrospinous ligament suspension associated with a paravaginal repair with mesh: short-term clinical results of a pilot study. Int Urogynecol J Pelvic Floor Dysfunct 21 (3):293-298

58. Jia X, Glazener C, Mowatt G, Jenkinson D, Fraser C, Bain C et al (2010) Systematic review of the efficacy and safety of using mesh in surgery for uterine or vaginal vault prolapse. Int Urogynecol J Pelvic Floor Dysfunct 21(11):1413-1431

59. Jacquetin B, Fatton B, Rosenthal C, Clave H, Debodinance P, Hinoul $\mathrm{P}$ et al (2010) Total transvaginal mesh (TVM) technique for treatment of pelvic organ prolapse: a 3-year prospective follow-up study. Int Urogynecol J Pelvic Floor Dysfunct 21 (12):1455-1462

60. Dwyer P, O'Reilly B (2004) Transvaginal repair of anterior and posterior compartment prolapse with Atrium polypropylene mesh. BJOG 111(8):831-836

61. Handa V, Zyczynski HM, Brubaker L, Nygaard I, Janz N, Richter HE et al (2007) Sexual function before and after sacrocolpopexy for pelvic organ prolapse. Am J Obstet Gynecol 197(6):629.e1629.e6

62. Zyczynski HM, Carey MP, Smith AR, Gauld JM, Robinson D, Sikirica V et al (2010) One-year clinical outcomes after prolapse surgery with nonanchored mesh and vaginal support device. Am J Obstet Gynecol 203(6):587, e1-8

63. Hoda MR, Wagner S, Greco F, Heynemann H, Fornara P (2010) Prospective follow-up of female sexual function after vaginal surgery for pelvic organ prolapse using transobturator mesh implants. J Sex Med 8(3):914-922

64. Lukban J, Roovers J, Moore RD, Patel M, Courtieu C, Mayne C (2010) A prospective multicenter study evaluating Elevate TM apical and posterior for treatment of posterior and/or apical vagnial wall prolapse: 12 month follow-up. Int Urogynecol $\mathrm{J}$ Pelvic Floor Dysfunct 21(suppl 1):s405-s406

65. Touboul C, Nizard J, Fauconnier A, Bader G (2008) Major venous hemorrhagic complication during transvaginal cystocoele repair using the transobturator approach. Obstet Gynecol 111(2 Pt 2):492-495

66. Emmanuelli E, Rubod C, Poncelet E, Lucot J-P, Quinton J-F, Cosson M (2010) Cure de rectocèle par prothèse type Transvaginal Mesh et compression rectale: à propos de trois cas. Pelvi-périnéologie 5 (4):243-246 